\title{
Is there a role for bronchial thermoplasty in the treatment of asthma?
}

\author{
Louis-Philippe Boulet MD FRCPC, Michel Laviolette MD FRCPC
}

\author{
L-P Boulet, M Laviolette. Is there a role for bronchial thermoplasty \\ in the treatment of asthma? Can Respir J 2012;19(3):191-192.
}

Bronchial thermoplasty is a new technique proposed to improve control of moderate to severe asthma. It delivers thermal energy to the large airways during a bronchoscopy to decrease the amount of bronchial smooth muscle. This intervention has been shown to reduce asthma exacerbations, and improve asthma control and quality of life over a three-year period without significant complications up to a five-year period. It could be considered as another option in the treatment of selected patients requiring oral and/or high doses of inhaled corticosteroids to control asthma. It should, however, be performed in specialized centres in patients who understand the potential benefits and side-effects of this technique. The response to this treatment varies from one patient to another. Consequently, further studies are required to better define the role of this option in the treatment of asthma.

Key Words: Asthma treatment; Bronchial thermoplasty; Interventional bronchoscopy; Moderate asthma; Severe asthma

The present review addresses the possible role of bronchial thermoplasty (BT) in the treatment of asthma.

\section{METHODOLOGY}

We reviewed the reports of clinical trials of BT in asthma (1-4), two reviews of the topic (5-6), a meta-analysis (7), six reports on safety $(8-13)$ and combined this information with our own experience with this procedure.

\section{OVERVIEW}

Asthma remains a common respiratory ailment and there is still a need to find new therapeutic avenues, particularly for moderate to severe asthma (14). BT has been developed in the past decade using radiofrequency for delivering thermal energy to the airways through the Alair catheter (Boston Scientific, USA) during bronchoscopy (15). The expandable wire array at the tip of the Alair catheter is expanded under direct vision to make contact with the airway wall and activated to heat $\left(65^{\circ} \mathrm{C}\right)$ the bronchial mucosa. This technique requires three bronchoscopy sessions (approximately $45 \mathrm{~min}$ each) separated by approximately three weeks to treat all pulmonary lobes apart from the right middle lobe. It requires gentle handling of the catheter and sustained attention to avoid trauma to the airways and to treat them only once by contiguous activations, distal to proximal. It has been hypothesized that the heat delivered by this intervention reduces the amount of airway smooth muscle (15). However, the evidence for this mechanism in humans is limited to eight subjects who underwent BT before lung surgery in which the treatment was limited to areas of segmental bronchi within the lobe that was to be removed (8). No data are available on the effects of BT on inflammatory and remodelling features of asthmatic airways.

\section{EFFICACY}

An initial feasibility study involving patients with mild to moderate asthma was conducted in two centres with a two-year follow-up. BT

\section{La thermoplastie bronchique a-t-elle un rôle à jouer dans le traitement de l'asthme?}

La thermoplastie bronchique est une nouvelle technique proposée pour améliorer le contrôle de l'asthme modéré à grave. Elle envoie de l'énergie thermique aux grandes voies aériennes pendant une bronchoscopie pour réduire la quantité de tissus du muscle lisse de la paroi bronchique. Il est démontré que cette intervention réduit les exacerbations de l'asthme et améliore le contrôle de l'asthme et la qualité de vie sur une période de trois ans, sans complications significatives pendant une période pouvant atteindre cinq ans. On pourrait l'envisager comme possibilité thérapeutique auprès de patients sélectionnés ayant besoin de corticoïdes par voie orale ou de fortes doses de corticoïdes en aérosol pour contrôler leur asthme. Il faut toutefois l'effectuer dans des centres spécialisés, auprès de patients qui comprennent les avantages et les effets secondaires potentiels de cette technique. La réponse au traitement varie d'un patient à l'autre. Par conséquent, d'autres études s'imposent pour mieux définir le rôle de cette possibilité dans le traitement de l'asthme.

improved peak inspiratory flows and reduced airway hyper-responsiveness over this period (1). Thereafter, three randomized clinical trials included patients with moderate to severe asthma (2-4). The first study (Asthma Intervention Research [AIR] trial) (2) from 11 centres worldwide included asthmatic subjects who required inhaled corticosteroids (ICS) and long-acting beta 2 -agonists (LABAs) to control asthma. There were 56 subjects in the BT group and 56 in the control group (usual care). The intervention group experienced a significant reduction in exacerbations at three and 12 months; at 12 months, there were significantly greater improvements in the BT group in morning peak expiratory flow, asthma quality of life (AQLQ) and asthma control.

Another study (Research in Severe Asthma [RISA] trial) (3) included subjects with symptomatic asthma despite treatment with high-dose asthma controllers and compared 15 BT-treated subjects with 17 subjects receiving usual care. An attempt at weaning oral or ICS was undertaken between weeks 22 and 36. At 52 weeks, oral corticosteroids (prednisone) and ICS were reduced by $63.5 \%$ and $28.6 \%$, respectively, in BT-treated subjects compared with $26.2 \%$ and $20 \%$, respectively, in control subjects. Despite taking reduced medications, BT-treated subjects showed a significant improvement in rescue medication needs, quality of life score and asthma control score.

The final clinical trial (AIR2) (4) included subjects who were symptomatic despite high doses of ICS and LABAs, and compared 190 subjects randomly assigned to active BT and 101 to sham BT. Compared with the sham-BT group, the intervention improved AQLQ score and reduced the rate of severe exacerbations by $32 \%$, the days lost from work, school or daily activities because of asthma symptoms by $66 \%$ and the number of emergency room visits by $84 \%$. Recent reports demonstrated that these benefits were maintained at two years (9) and three years (11). It has been our experience that some subjects significantly improved whereas others did not, suggesting that a subgroup of asthmatic subjects may respond favourably to BT, although response cannot be predicted.

Institut universitaire de cardiologie et de pneumologie de Québec, Québec

Correspondence: Dr Louis-Philippe Boulet, Institut universitaire de cardiologie et de pneumologie de Québec, 2725 Chemin Sainte-Foy,

Québec, Québec G1V 4G5. Telephone 418-656-4747, fax 418-656-4762, e-mail lpboulet@med.ulaval.ca 


\section{SHORT-TERM SAFETY}

In the four clinical trials (1-4), side effects following BT were transient, resolved within one week and were relatively similar to those observed after bronchoscopy in patients with asthma. Side effects were more marked in subjects with more severe asthma and required hospital admissions in some cases. In the Air2 study, there were slightly more respiratory symptoms and hospital admissions during the treatment periods after active thermoplasty than after sham thermoplasty. Wilson et al (12) reported that patients who completed the three treatment procedures showed a high level of satisfaction with the procedure; this was also our experience with patients participating in the clinical trials in which we were involved (2-4).

\section{LONG-TERM SAFETY}

The safety of the treatment beyond the end of the clinical trials for up to two to five years has been maintained $(9-11,13)$. There were no increases in respiratory adverse effects and health care utilization, and no decrease in lung function over these periods. In the AIR2 study, blinded comparison of high-resolution computed tomography scans at baseline and 12-month follow-up from 100 bronchial thermoplasty and 50 sham subjects showed no structural changes in the lung (6). No bronchial dilation, bronchiectasis, bronchiolitis obliterans or pulmonary emphysema were noted in any of the BT-treated subjects one year after the treatment.

\section{RECOMMENDATIONS FOR CLINICAL PRACTICE AND FUTURE RESEARCH}

There is convincing evidence that this treatment is safe when performed by experienced physicians, and that it can improve markers of asthma control and severity. However, additional long-term clinical trials are needed to confirm the benefits of BT in the treatment of moderate to severe asthma and to better identify the subgroup of subjects that could better benefit from this treatment. The mechanisms underlying its beneficial effects must be further evaluated in humans. It would be of particular interest to determine whether it acts primarily in subjects with greater increases in the smooth muscle area of their large airways.

The 2011 update of the Global Initiative for Asthma report (www. ginasthma.com) indicates that "For adult patients whose asthma remains uncontrolled despite application of this therapeutic paradigm, and referral to an asthma specialty center, bronchial thermoplasty is now a possible option in some countries. The treatment, which itself is associated with asthma exacerbations in the months post bronchoscopy, results in a subsequent decrease in exacerbations. There are no significant effects on lung function or asthma symptoms. The safety and efficacy of thermoplasty beyond one year is not known. Caution should be used in selecting patients for this procedure".

We believe, however, that taking into account the more recent data shown above and from our experience with this technique over the past eight years, this treatment could become another option to help reduce the need for oral and/or high doses of ICS and improve asthma control in some selected moderate to severe asthma patients.
However, as stated above, the subjects considered for this technique, which should only be performed by trained physicians, must be carefully evaluated before the procedure, understand the potential benefits and side-effects of this technique and be closely followed during the year following the procedure. Finally, the cost-benefit ratio of the procedure must be determined.

\section{REFERENCES}

1. Cox G, Miller JD, McWiliams A, Fitzgerald JM, Las S. Bronchial thermoplasty for asthma. Am J Respir Crit Care Med 2006;173:965-9.

2. Cox G, Thomson NC, Rubin AS, et al. Asthma control during the year after bronchial thermoplasty. N Engl J Med 2007;356:1327-37.

3. Pavord ID, Cox G, Thomson NC, et al. Safety and efficacy of bronchial thermoplasty in symptomatic, severe asthma. Am J Respir Crit Care Med 2007;176:1185-91.

4. Castro M, Rubin AS, Laviolette M, et al. Effectiveness and safety of bronchial thermoplasty in the treatment of severe asthma: A multicenter, randomized, double-blind, sham-controlled clinical trial. Am J Respir Crit Care Med 2010;181:116-24

5. Cox G. Bronchial thermoplasty for severe asthma. Curr Opin Pulm Med 2011;17:34-8.

6. Castro M, Musani AI, Mayse ML, Shargill NS. Bronchial thermoplasty: A novel technique in the treatment of severe asthma. Ther Adv Respir Dis 2010;4:101-16.

7. Wu Q, Xing Y, Zhou X, Whang D. Meta-analysis of the efficacy and safety of bronchial thermoplasty in patients with moderate-to-severe persistent asthma. J Int Med Res 2011:39:10-22.

8. Miller JD, Cox G, Vincic L, Lombard CM, Loomas F, Danek CJ. A prospective feasibility study of bronchial thermoplasty in the human airway. Chest 2005;127:1990-2006.

9. Castro M, Rubin A, Laviolette M, Hanania NA, Armstrong B, Cox G; for the Air2 Trial Study Group. Persistence of effectiveness of bronchial thermoplasty in patients with severe asthma. Ann Allerg Asthma Immunol 2011;107:65-70.

10. Cox G, Laviolette M, Rubin A, Thomson N. Long term safety of bronchial thermoplasty (BT): 3 year data from multiple studies. Am J Respir Crit Care 2009; 179:A2780.

11. Thomson NC, Rubin AS, Niven RM, et al; the Air Trial Study Group. Long-term ( 5 year) safety of bronchial thermoplasty: Asthma Intervention Research (AIR) trial. BMC Pulmon Med 2011;11:8.

12. Wilson S, Cox G, Miller JD, Lam S. Global assessment after bronchial thermoplasty: The patient's perspective. J Outcome Res 2006;10:37-47.

13. Laviolette M, Rubin AS, Pavord I, Thomson N, Niven R, Cox G. Safety of bronchial thermoplasty out to 5 years in patients with severe refractory asthma: Research in severe asthma (RISA) trial. Eur Respir J 2011;(Suppl):607s, Abstract 3422.

14. Masoli M, Fabian D, Holt S, Beasley R; Global Initiative for Asthma (GINA) Program. The global burden of asthma: Executive summary of the GINA Dissemination Committee report. Allergy 2004;59:469-78.

15. Cox P, Miller J, Mitzner W, Leff Al. Radiofrequency ablation of airway smooth muscle for sustained treatment of asthma: Preliminary investigations. Eur Respir J 2004;24:659-63. 


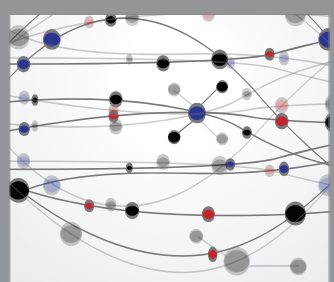

The Scientific World Journal
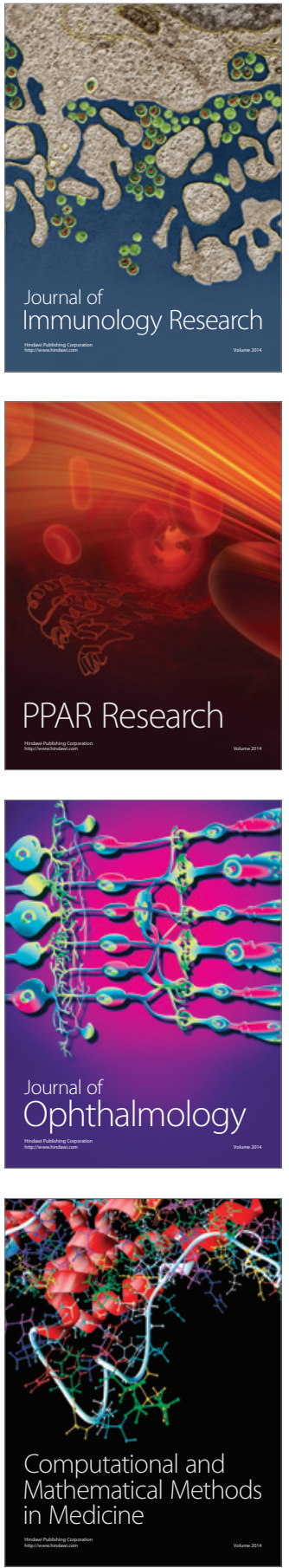

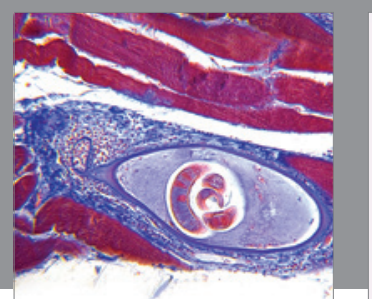

Gastroenterology Research and Practice

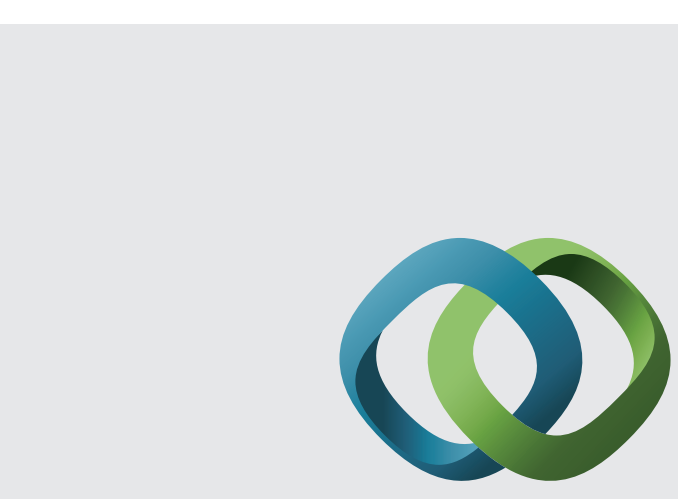

\section{Hindawi}

Submit your manuscripts at

http://www.hindawi.com
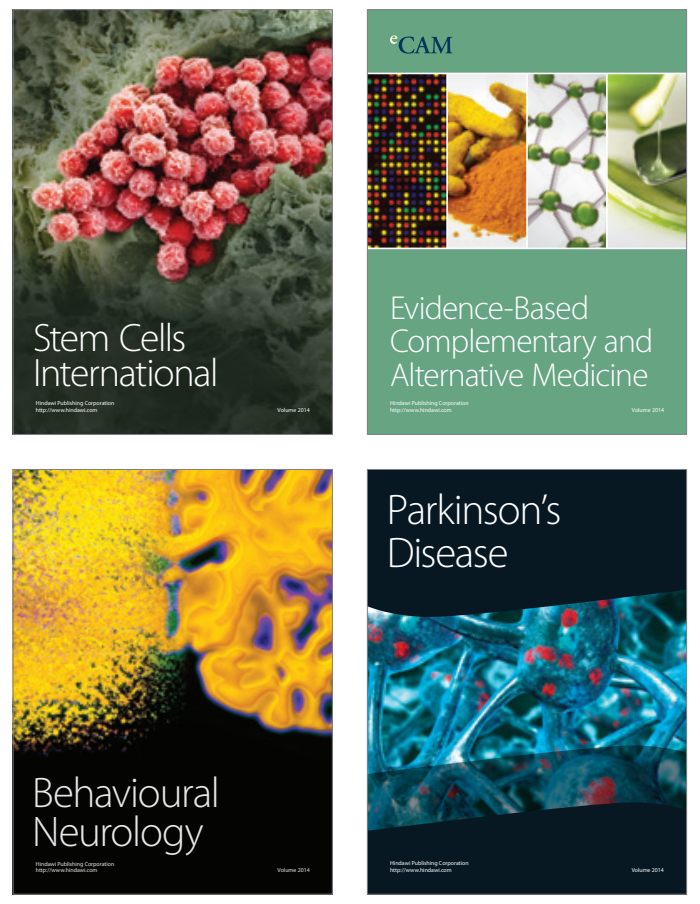
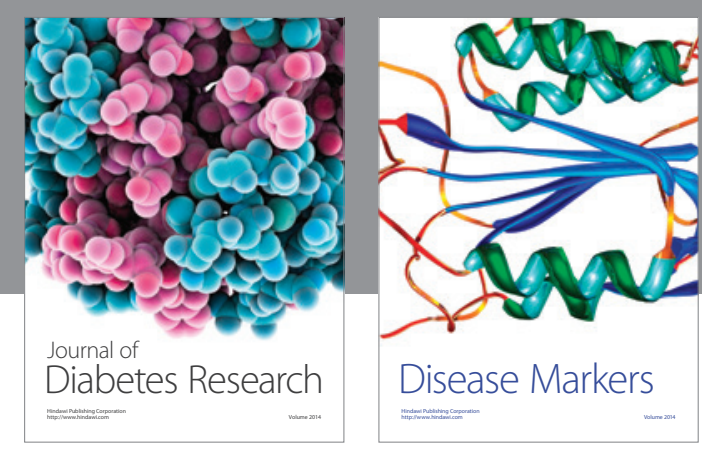

Disease Markers
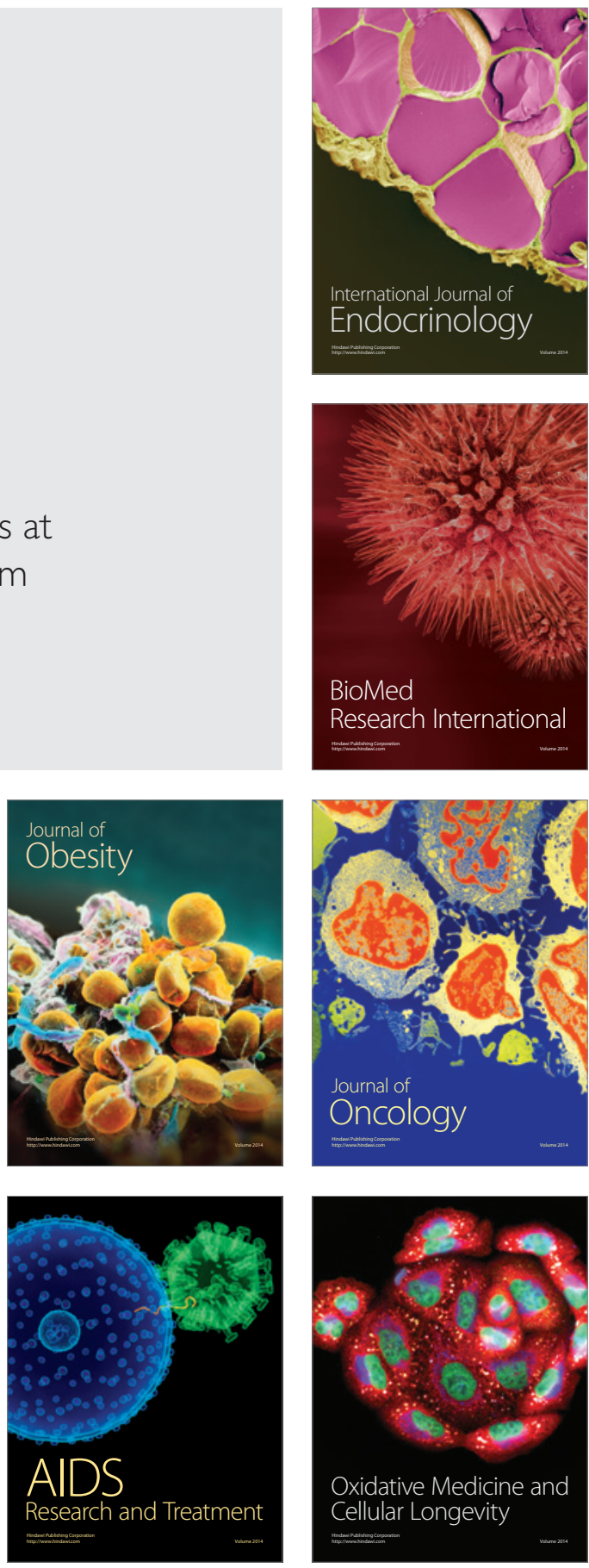